\title{
HLA Class I Histocompatibility Antigen, A- 0201 Alpha Chain Positive
}

National Cancer Institute

\section{Source}

National Cancer Institute. HLA Class I Histocompatibility Antigen, A-0201 Alpha Chain

Positive. NCl Thesaurus. Code C129450.

Indicates that HLA class I histocompatibility antigen, A-0201 alpha chain expression has been detected in a sample. 